\title{
THE ONTARIO RESEARCH FOUNDATION
}

$\mathrm{T}$ HE report of the Ontario Research Foundation for the year 1940 includes the Director's report together with the financial statment and a full list of publications to December 31, 1940. The Director's report refers to the new problems created for those engaged in agriculture, particularly to work concerned with remedying the slow depletion of the soil. The Foundation is studying areas which show evidence of trace-element depletion and also characteristic deficiency diseases, such as boron deficiency in the apple, sugar beet and turnip, copper deficiency in the onion and manganese deficiency in oats. A survey of land values in rural Ontario and their relation to soil, climate and economic factors has been commenced. The work on mastitis in cows has continued throughout the year and evidence has been secured proving that the leucocytes present in milk can destroy the characteristic bacteria which are associated with mastitis. A study of the pathological changes in the udder of the cow caused by tuberculosis and other diseases has been commenced.

In the late autumn the pathological and bacteriological staff were fully occupied in field studies of autopsies and laboratory work arising from a widespread outbreak of a respiratory disease among young pigs. Rapid and successful progress has been made in investigating the life-history of a parasitic fly which attacks and destroys the larvæ of the clothes moth. The research has indicated other problems related to the use of parasites for the destruction of pests and also to the nature of the physiological relation between the host and the parasite.

The work of the Textile Department has continued to expand, and much of its testing work in 1940 was in connexion with fabrics and other materials manufactured for war supplies. Co-operative work with various firms associated with the quality control plan, in which eighteen manufacturers of fabrics and eighty manufacturers of garments are now cooperating, has been concerned particularly with work on the relation between. seam construction and serviceability, effects of different finishing processes on the strength of dress fabrics, a comparative study of length of life of wool socks and wool plus rayon socks and the influence of time and other factors on the extensibility of drapery fabrics. Work on the response of silk to water vapour has been extended to cover a number of organic substances such as alcohols, ethers and ketones.

The investigation of the principles of scouring has continued, while in the Division of Engineering and Metallurgy, in addition to important testing work, studies have continued on the resistance of various alloys to abrasion, the malleability of white cast iron in relation to variation in chemical composition and the influence of the cross-sectional area of a test piece on the fatigue strength as measured by the Avery machine.

The Chemistry Division has largely been concerned with analytical work in connexion with specifications, while in the Division of Biochemistry, research in the leather laboratory has been concerned with further improvements in the methods of intermediate alum and chrome re-tannage of heavy leathers. Work has continued on methods for the preparation of organic acids by fermentation as well as the prepara. tion of pure lactic acid for edible and medicinal purposes. Much of the effort of the Biochemistry Division has been given to determinations of vitamins in mill and other food products. The Department is collaborating in the development of rapid cheap and reliable methods for the determination of vitamin $B_{1}$, and is already in a position to carry out accurately and economically biological or chemical assays of vitamins $A, C, D$ and $B_{1}$ constituents and riboflavin.

\section{USES OF THE 200-IN. TELESCOPE}

$\mathrm{D}^{\mathrm{R}}$ R. MAX MASON, chairman of the Observatory Council of the California Institute of Technology, speaking at a meeting in June of the Pacific Division of the American Association for the Advancement of Science and the Astronomical Society of the Pacific, stated that the great 200-inch telescope to be erected on Mt. Palomar is now approaching completion, thirteen years after the late Dr. George Ellery Hale convinced the Rockefeller Boards of the feasibility of such an instrument, and obtained funds for its construction. It will be recalled that Dr. H. Spencer Jones gave some details about this instrument in his Thomas Young Oration before the Physical Society (Nature, June 14, p. 753).

The disk, about $17 \mathrm{ft}$. in diameter, originally weighed 21 tons, and during five years' grinding at Pasadena, more than four tons of glass have been removed. The disk is carried by a system of thirty-six levers inserted in the holes of the ribbed back. Both the method of support and the structure of the mirror are new in this instrument. The supporting system must operate so perfectly that no bending of the reflecting surface beyond one or two millionths of an inch will occur as the telescope moves. As the surface of the mirror was brought by polishing close to a spherical form it became clear that the disk, when tipped from the grinding table to a vertical position for optical test, sagged slightly under gravity. This sag has now been eliminated by installing a system of twenty-four squeeze levers, operated by counter weights, distributed around the rim of the glass. The spherical surface required has nearly been reached, after which it will be changed to a paraboloid by deepening the centre concavity five thousandths of an inch.

Dr. Mason stated that it is doubtful whether the new instrument will be useful for photographing moon or planets, due to shakiness of the air, which destroys detail. Instead it will be used to study faint and distant galaxies, and to analyse in high detail light from the stars and planets.

Dr. John Strong, also of the California Institute of Technology, stated that one of the uses of the 200 -in. 
telescope will be to study planetary radiations. Planets not only reflect visible light which they receive from the sun; they absorb and then reradiate considerable quantities of solar energy, largely in the form of the invisible infra-red rays. The special instruments and techniques necessary for the analysis of these radiations are being developed by members of the Institute staff. Much of the information necessary for comparison of conditions on the planets with those on the earth can be obtained only by a more careful and exact study of physical processes taking place on the earth's surface and in its atmosphere. Determinations, to an entirely new order of exactness, of the effect of water vapour, carbon dioxide, ozone and the major atmospheric gases on radiation, are on the programme of research. Incidentally, Dr. Strong pointed out, data obtained in these researches will probably be of very con. siderable value to meteorologists as well as to astronomers.

\section{EQUATORIAL REGIONS OF THE PACIFIC}

T his address on June 18 as president of the Pacific Division of the American Association for the Advancement of Science, Dr. H. U. Sverdrup, 'director of the Scripps Institution of Oceanography, stated that the Pacific Ocean is two feet higher on the Australasian side than it is on the American.

As a result of this difference in elevation, there is a narrow, relatively swift current flowing eastward along the equator. If it were not for the friction of water against water, it would move at a rate of about seven knots. Its actual rate is one or two knots. This, however, is as rapid as the current in a great many inland rivers.

The pile-up of water against the Pacific's western shore results from the action of the trade winds. Steady winds blowing across the water from the north-oast in the northern hemisphere's lower latitudes, and corresponding winds from the south-east in the southern hemisphere, keep two great currents moving steadily westward in the tropical Pacific.
Separating them, in the equatorial belt of calms, is the narrow return current, flowing like a river.

This narrow west-to-east equatorial current, however, accounts for only a small part of the water returned across the Pacific. Much larger streams flow away from the equator, to make the return trip at higher latitudes. In the northern hemisphere, the principal returning mass is borne in the Kuroshio or Japan current, which sweeps along the Aleutian chain and turns southward along the North American coast. It is estimated that this current carries more than five thousand times as much water as the Mississippi.

As described by Dr. Sverdrup, the Pacific is a cold monster with a relatively thin, warm skin. Surface temperatures are quite high, reaching as much as $75^{\circ} \mathrm{F}$. But this warm surface layer extends downward only a few hundred feet at most. The great bulk of Pacific ocean water, in the depths, is always cold, most of it only a few degrees above freezing-point.

\section{EXTRACTION OF GOLD FROM SEA-WATER}

$\mathrm{W}$ ITH about five million pounds worth of gold dissolved in each cubic mile of sea-water, man has often sought a way of digging out this treasure. Using electrochemical methods, comparable to those used in electroplating, gold has actually been extracted from the ocean, but unfortunately the cost of the process is five times the value of the gold obtained.

Hopes that this may be reduced to the point where gold may be profitably extracted were raised by Dr. Colin G. Fink, of Columbia University, speaking before the Wilder D. Bancroft Colloid Symposium at Cornell University.

In electroplating, the metal in the plating solution is deposited on the cathode, the negative terminal. But when an effort is made to plate the gold out of sea water in this way the metal precipitates out rapidly, and fails to collect in the solid, crystalline form in which it is desired. By using a rapidly spinning cathode in place of the stationary one, it has been found possible to get a distinctly visible gold deposit. It is the cost of providing the spinning cathode that makes the method impracticable commercially.
In his search for the reason why gold fails to deposit on the stationary cathode, Dr. Fink made the discovery that, when gold passes out of or into solution, two distinct steps are involved. Invisible dissolved gold first goes into myriads of minute particles of colloidal gold, and then later into the crystalline form of the metal. The stationary cathode fails because the metal precipitates out in colloidal form and drops away before crystallizing.

Now a problem remains, namely, conversion of the colloidal gold into the metal crystals. Perhaps it can be accomplished with high-voltage electric currents, or with bombardment of electrons. Dr. Fink intends to try these. "In any event," he said, "it is felt that, on the basis of the discovery, we have advanced one step closer to the commercial recovery of gold from sea water."

Apart from this, however, the discovery is of great theoretical significance, and has practical importance as well. For example, it may hasten development of formulæ for the electroplating of metals such as titanium and vanadium. In this way, it may have far-reaching commercial results whether the gold extraction is accomplished or not. 